Infirmary, Glasgow, comparing sequelae of spinal and general anaesthesia. Unselected patients requiring surgical repair of fractured neck of femur were randomly allocated to receive either spinal anaesthesia with $1 \cdot 3-1 \cdot 5$ $\mathrm{ml}$ of heavy cinchocaine hydrochloride (Nupercaine), with minimal sedation with diazepam if necessary, or general anaesthesia induced with Althesin (alphaxalone and alphadolone) and maintained with spontaneous ventilation with halothane in nitrous oxide and oxygen. In the first 140 patients studied we found a significantly lower mortality in the spinal anaesthetic group $-6 \%$ compared with $18^{\circ} \%$ of the general anaesthetic group-in the first three weeks after operation. A cluster of deaths occurred between the sixth and the 18 th postoperative days in the general anaesthetic group only. The deaths which occurred in the spinal anaesthetic group were evenly spread over the three-week period. The timing of deaths would suggest a thromboembolic aetiology. A study including venography is now under way and full results of these studies will be published in due course.

It is interesting that changes in blood viscosity and red cell deformability examined in our patients ${ }^{3}$ were in keeping with the hypothesis of a thrombotic or thromboembolic aetiology. Spinal anaesthesia produced a fall in viscosity and made red cells more flexible; general anaesthesia had approximately the opposite effect.

Peter J McKenzie

Nuffield Department of Anaesthetics,

Radcliffe Infirmary,

HUGH Y WISHART

Department of Anaesthetics,

Western Infirmary,

${ }^{1}$ Lóudon JR, McGarrity G, Vallance R, Baylis AC Graham J. Br F Surg 1978;65:616-8.

McKenzie PJ, Wishart HY, Dewar KMS, Gray I, Smith G. Br f Anaesthesia 1980;52:49-54

Drummond AR, Drummond MM, McKenzie PJ, Lowe GDO, Smith G, Wishart HY. Thromb Res (in press).

\section{Transient cardiac arrhythmias and fractures of the femur}

SIR, - We are surprised at the comments made by Drs Michael Lye and Rodrigues Dos Santos on the incidence of transient cardiac arrhythmias in elderly patients with fractures of the femur (3 January, p 73).

Considerable confusion exists about what constitutes a "significant" arrhythmia in the elderly. According to Lown's criteria, ${ }^{1}$ with which we would agree, major ventricular arrhythmias include frequent ventricular premature contractions (VPCs) greater than 30/hour, multiform VPCs, paired VPCs, ventricular bigeminy, salvoes of VPCs, and ventricular tachycardia. Sinus arrest, sinoatrial block, second and third degree atrioventricular block, and sustained supraventricular tachycardias, including paroxysmal and established atrial fibrillation, should also be classified as major arrhythmias.

In our own study of 106 healthy people aged 75 years and over, which is the largest sample of this population age group yet reported, we found that $30 \%$ had major ventricular arrhythmias and a further $1 \%$ had intermittent complete heart block. ${ }^{2}$ We found no instances of sinus arrest and sinoatrial block, although other features of sinus node disease were seen more frequently, such as a fixed sinus rate $(30 \%)$, severe sinus bradycardia $(10 \%)$, and atrial fibrillation $\left(11_{0}^{\circ}\right)$. It is true, however, that arrhythmias detected by 24-hour ambulatory electrocardiographic (ECG) monitoring are very frequent in this elderly age group and we found that only $23^{\circ} \%$ had completely normal 24-hour tapes.

With regard to falls, the usual cause of femoral neck fractures, our recent investigations suggest that it is severe bradycardic states, including sinus arrest and sinoatrial block, that are found in ECG monitoring rather than tachycardias. Since the resting 12-lead electrocardiogram will rarely identify intermittent episodes of conduction system block, 24-hour ambulatory ECG monitoring and "events" monitoring are the only satisfactory methods at present available for detecting these.

Thus, despite the poor correlation between symptoms and abnormalities found in ambulatory monitoring in the elderly, ${ }^{2}$ we believe that there is a place for long-term ECG monitoring in patients with femoral fractures. This is the only way to identify the small, but significant, incidence of treatable intermittent conduction system block that occurs in these patients and which is not found in the healthy elderly population.

ANTHONy MaRTIN

Department of Geriatric Medicine,

ospital,

Crawley, Sussex

Department of Cardiology, Despita,

\section{Lown B, Wolf M. Circulation 1971;44:130-42.} amm AJ, Evans KE, Ward DE, Martin A. Am Heart f 1980;99:598-603.

\section{Early discharge after acute myocardial} infarction

SIR, - We were greatly encouraged by the paper of Dr Y K Lau and others (21 June 1980, p 1489) on early hospital discharge for low-risk myocardial infarction patients. This report should have a profound effect on stimulating further research into ways to halt soaring medical costs.

From 31 May 1978 to 31 October 1980, we saw 37 patients who had no recurrent chest pain, arrhythmia, pericardial rub, or congestive heart failure and who were transferred to an intermediate coronary care unit 48 hours after their heart attack, where they were allowed to walk $25 \mathrm{~m}$ three times a day between meals. If no symptoms of chest pain or signs of undue tachycardia occurred they were allowed to walk on the regular medical floor, which is about $120 \mathrm{~m}$ in length. They were monitored by frequent pulse rate and blood pressure checks, electrocardiography, or heart monitor. If they continued to do well they were discharged on the seventh or eighth day. Eight to 10 weeks later all 37 patients were returned for treadmill tests and 26 of them were in class I (Bruce protocol). They were then allowed to return to full-time employment.

We have seen many patients who were depressed because they were hospitalised too long with too little to do, and had no supervised rehabilitation. Speeding up the hospital stay and employing close observation by trained nurses, physiotherapists, and cardiac monitoring better occupies the patient's time and removes their in-hospital anxiety. This step-by-step approach has restored patients' faith in themselves, and, in uncomplicated conditions, they can return to being productive members of society in a short period of time.

Tien C Cheng

St Therese Hospital,

Waukegan, Illinois 60085,

USA

McNeer JF, Wagner GS, Ginsburg PB, et al, $N$ Engl f Med 1978;298:229-32.

\section{Calcium antagonists and the heart}

SIR,-Your leading article on calcium antagonists and the heart (10 January, p 89) in a laudable attempt to simplify the issues makes one or two errors of fact. You state, "Drugs which antagonise the ingress of calcium through the channels in cell membranes may therefore have two actions: they may alter cardiac rhythm or they may act as vasodilators." The whole of your previous paragraph is concerned with the way in which calcium is involved in contractility, and this surely constitutes a third, quite separate action-namely, negative inotropism.

The four drugs which you list as calcium antagonists express their three actions in varying degrees as their principal effect on the cardiovascular system. Lidoflazine, surprisingly absent from the list, clearly exhibits a fourth action by inhibiting excessive ingress of calcium into cells deprived of oxygen without, however, affecting calcium homoeostasis in the well-oxygenated cells. ${ }^{12}$ This mechanism may well be the basis for the undoubted clinical efficacy of lidoflazine in angina pectoris. ${ }^{3}$

The phrase calcium antagonist now clearly encompasses several compounds with distinctly different clinical effects. It is not appropriate to take words in common usage and, like Humpty Dumpty in Alice through the Looking Glass, use them to mean whatever we want them to mean. Since calcium can enter and leave cells by routes other than the so-called "slow channel"' the term calcium antagonist should include any agent whose predominant action is to block or modify calcium fluxes across the cell membrane. Subdivision of the term calcium antagonist into four or more classes based on their principal therapeutic effects might enable us to define the individual role of each of these interesting compounds in the treatment of cardiovascular disease more clearly.

A L MACNAIR

H A WALDRON

Janssen Pharmaceutical Limited,

Marlow, Bucks SL7 1E'

Flameng W, Daenen W, Xhonneux R, Van de Water A, Thone F, Borgers M. Proc $R$ Soc Med $1980 ; 29$ A, 94 .

2 Nayler WG. Proc $R$ Soc Med 1980;29:79-87. 3 Nordstrom LA, Gobel FL. Chest 1978;74:50-4.

Nayler WG. Eur Heart $\mathcal{f}$ 1980;1:225-37.

\section{Percutaneous subclavian vein} catheterisation and tunnelling procedures

SIR,-We read with interest the "Lesson of the Week" concerning the late appearance of a pneumothorax after infraclavicular subclavian vein catheterisation reported by $\mathrm{Mr}$ A Mitchell and $\mathrm{Mr} \mathrm{H}$ W Steer (15 November, $p$ 1339) and also the comments of $\mathrm{Mr} \mathrm{J}$ Bancewicz and others (27 September, $p$ 871) on our technique of using a Sonicaid Doppler probe to detect the subclavian vein and artery prior to the 